The Complex Process of Scaling the Integration of Technology Enhanced Learning in

Mainstream Classrooms

Alison Clark-Wilson

UCL Knowledge Lab, University College London, 23-29 Emerald Street London WC1N 3QS

a.clark-wilson@ucl.ac.uk

\begin{abstract}
The early optimism for how technology might transform teaching and learning practices in mainstream school classrooms has long faded in many countries around the world. Whilst early research findings suggested that this was due to obvious barriers such as access to the technology itself, more recent attempts to scale student-access have illuminated other factors and provided a more sound theoretical foundation for us to understanding the processes and products of scaling educational technology innovations. This keynote will use findings from key projects and initiatives to highlight what is being learned and how this might inform future endeavours to realise a more $21^{\text {st }}$ century curriculum.
\end{abstract}

\title{
1 Introduction and Overview
}

This paper summarises the keynote presentation given at CSEDU 2016 in Rome that aimed to highlight the complexity of the processes of integration of educational technology in mainstream classroom. What follows is a brief overview of the talk.

There are many interpretations of how digital technologies impact upon learners' educational experiences in the broadest sense. I begin by drawing on the ideas of two early visionaries, Burrhus Skinner and Seymour Papert, on order to contrast their very different perspectives on children's learning experiences during school education. I then use the example of a current large-scale longitudinal research study in England to highlight the processes and products of scaling that is providing substantial research evidence to enable us to characterise features of successful widespread implementations. I conclude by highlighting the implications of these findings and suggest questions for future research and further consideration by the educational technology design and research communities.

PRE-PRINT Clark-Wilson, A. (2017). The Complex Process of Scaling the Integration of Technology Enhanced Learning in Mainstream Classrooms. In G. Costagliola, J. Uhomoibhi, S. Zvacek, \& B. M. McLaren (Eds.), Computers Supported Education: 8th International Conference, CSEDU 2016, Rome, Italy, April 21-23, 2016, Revised Selected Papers (pp. 3-13). Cham: Springer International Publishing. 


\section{Early Optimism - The Visionaries in Education}

Technology is not a new idea in education. There have been significant attempts at technology integration in education since the early 1900s. For example, the introduction of paper and pencil caused much anxiety for teachers who had developed confident practices in their classrooms with the traditional classroom slate, based on teacher exposition and rote learning. Teachers questioned why they should opt for a new technology that threatened aspects of their existing pedagogic approaches, such as the requirement to mark students' written work and hand it back to them. Worries about the spiraling costs of widespread implementation of paper and pencils were expressed - alongside concerns about the need for new pedagogies and classroom management techniques. The arrival of moving film in the 1910s promised another educational revolution - with pioneers such as Thomas Edison predicting widespread use of what we now call video in the future. The radio broadcasts of the 1920s prompted similar predictions. In my own primary school education in England during the 1960s we had radios on the wall of all classrooms and it was a commonly used media as the class sat to listen to stories and plays. Similarly for television in the 1950s and, with the arrival of computers to mainstream education in the 1970s, again came an early optimism and the promise of yet another educational technology revolution.

However, there were very different views on how all of these technologies might impact on the students learning experiences. I contrast the perspectives of two early visionaries to highlight this point.

The psychologist and social philosopher B.F Skinner, conceived an early mechanical teaching machine. In Skinner's vision of the classroom students worked individually and in silence as they responded to exercises that were administered and 'assessed' by the learning machine. See Figure 1.

Figure 1 A boy working on a teaching machine (c1950)

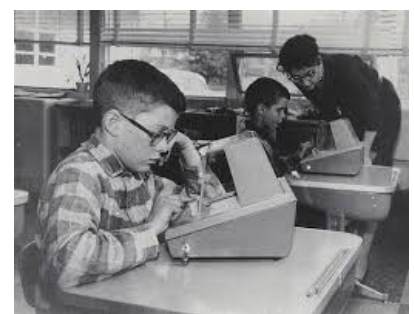

Skinner claimed that use of the teaching machine would lead to the "formation of correct behaviours - the student quickly learns to be right" by giving immediate feedback to students and, by doing so, students would be "free of uncertainty or anxiety about success or failure - his work is pleasurable" [1].

By contrast, the mathematician Seymour Papert, who was the father of constructionism, believed that computers could be an expressive medium for students' own 
mathematical ideas and creations saying "the idea is simple, let a child learn mathematics by speaking in mathematics about things that really matter to him" [2]. With colleagues at MIT, he developed the LOGO programming language and its most influential peripheral device, the floor turtle. See Figure 2.

Figure 2 Young children working with a LOGO floor turtle (c1980)

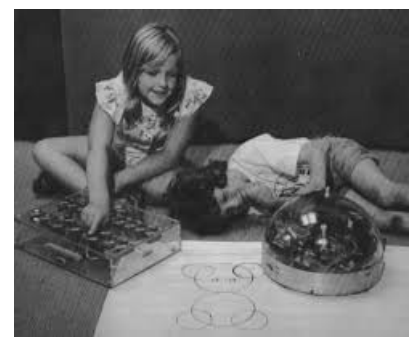

Furthermore, Papert believed that expressive mathematical media such as the LOGO computing language provided an opportunity to affect the nature of mathematical knowledge itself, leading to new computational approaches and insights into topics such as recursion and fractal geometry.

If we move to the present day, the internet abounds with millions of digital exercises in the spirit of Skinner's vision, and, even though the nature of the interactions and the opportunity for more nuanced and intelligent feedback are now possible, these resources are predominantly designed to provide fast and efficient ways to assess particular educational content that has already been taught. This prompts the question, what about the digital design of educational content that aims to introduce students to significant knowledge in the first place?

Within the mathematics education community, technology has been a topic of interest since the early 1980s. The International Commission on Mathematics Instruction (ICMI) held its very first topic study conference on The Influence of Computers and Informatics on Mathematics and its Teaching in 1985. During this conference mathematicians and mathematics educators explored the way the computer was influencing mathematics itself and the way in which mathematicians worked, its likely influences on the curriculum of high-school and undergraduate students, and the way in which the computer might be used to improve mathematics teaching and learning [3].

The topic was revisited by the community in 2008 within the $17^{\text {th }}$ ICMI Study on Mathematics Education and Technology - Rethinking the Terrain that focused on "cultural diversity and how this diversity impinges on the use of digital technologies in mathematics teaching and learning. Within this focus, themes such as mathematics and mathematical practices; learning and assessing mathematics with and through digital technologies; teachers and teaching; design of learning environments and curricula; implementation of curricula and classroom practice; access, equity and socio- 
cultural issues; and connectivity and virtual networks for learning, serve to organize the study and bring it coherence" [4]. In the opening editorial, Hoyles and Lagrange highlight a common concern within the mathematics education community that, despite early optimism for the potential for technology to transform school, college and university education, very little seemed to have changed in the intervening twenty years with respect to students' mathematical experiences as learners in classrooms. Mathematics education research concerning technology use has now shifted to focus more explicitly on the role of the teacher within technology mediated classrooms $[5,6]$. Researchers have begun to articulate the complexity of the teacher's role, which combines:

- Selecting appropriate technologies for teaching mathematical topics.

- Designing tasks that are mediated by chosen technologies.

- Supporting students to become familiar and confident users of the technology within the mathematical context (the processes of instrumentation and instrumentalisation [7]).

- Developing new pedagogies to employ productive use of the technology in whole-class, small group and individualised teaching.

- Adapting assessment practices to take account of students' digital work and productions.

\section{Two Important Definitions}

In the examples that follow, which are taken from mathematics education, there are two key terms that warrant deeper explanation: transformative mathematics technology and landmark activities.

\subsection{Transformative Mathematics Technology}

The earlier illustrative examples from Skinner and Papert demonstrate how the underlying affordances of the technological tool can shape and be shaped by the associated epistemology (and the potential pedagogies). It is possible to take the same tool and use it in very different ways within educational settings - the technology itself does not necessarily define its subsequent use. Artigue, referring to secondary mathematics teachers' uses of computer algebra software, commented on "an explosion of techniques which remain relatively ad hoc, and pose a didactic obstacle to the progressive building of mathematical activity instrumented in an efficient way"[8]. Consequently, my colleagues and I have defined the term transformative mathematics technology as a class of 'computational tools through which students and teachers (re)express their mathematical understandings' $[9,10]$. For teachers, these new mathematical understandings concern both the content matter and the related pedagogies. So when I begin to discuss the scaling of technology, I am referring to the scaling of this particular class of technologies, an example of which will be provided later.

$$
6
$$

PRE-PRINT Clark-Wilson, A. (2017). The Complex Process of Scaling the Integration of Technology Enhanced Learning in Mainstream Classrooms. In G. Costagliola, J. Uhomoibhi, S. Zvacek, \& B. M. McLaren (Eds.), Computers Supported Education: 8th International Conference, CSEDU 2016, Rome, Italy, April 21-23, 2016, Revised Selected Papers (pp. 3-13). Cham: Springer International Publishing. 


\subsection{Landmark Activities}

When considering both the design and evaluation of technology enhanced learning at scale, we use the notion of a landmark activity as one that is mediated by a disruptive but carefully designed task that prompts a cognitive breakdown, or a "situation of non-obviousness" [11]. These landmark activities serve two purposes:

- As focusing tasks for teachers during professional development. Teachers work through the landmark activities for themselves before working collaboratively with colleagues to plan and reflect upon how they intend to support their students through the planned moments of cognitive conflict within their particular classroom settings. This approach offers focused support for teachers as they begin to think how they will respond to a diversity of learner responses, supporting them to develop contingent knowledge.

- As a research methodology to support the evaluation of teachers' classroom implementations. i.e. during observations of the landmark activities being taught in the classroom, judgments can be made concerning the implementation fidelity of the intervention in relation to the design principles (For more on this theme, see [12]).

\section{The Current Picture Around the World}

Many countries are now grappling with issues that relate to the scaling of educational technology in mathematics classrooms. This is partly due to the more ubiquitous nature of technology - even in developing countries - but also due to the immense financial and human investments that have been made to this end.

Around the world, recent research highlights some common and recurring issues irrespective of the level of mathematics teaching. For example, it is common that teachers' early pedagogies with technology tend to emulate their traditional teaching approaches. Trigueros, Lozano and Sandoval concluded from their study in Mexican primary schools that "teachers, who have only received training on the general use of the software, without a hint of how to introduce them into specific lessons, often develop teaching strategies where technology is used as replacement or amplification" [13]. Many researchers also comment on the influence of teacher's confidence to teach using technology on their resulting practices. In New Zealand, Thomas and Palmer's study highlighted the "strong correlation between confidence in using technology in the mathematics classroom and pedagogical technological knowledge" [14] in a secondary school setting. Concerning teachers' motivations to use technology in their teaching, the research within undergraduate mathematics teaching in Canada by Buteau and Muller concludes that "overall it seems that the great majority of tutors who integrate technology into their mathematics teaching do so by their own volition" [15]. We know much about the issues and barriers that mitigate against teachers' take- 
up of technology in their mathematics teaching - but far less about the conditions that might lead to successful implementations on a regional or national scale.

In England, which provides the setting for the research that follows, the situation is:

- Most secondary mathematics students do not use transformational mathematics technology in lessons [16].

- Most English secondary schools are very well equipped with technology with ratios of computers to students in the region of 1:3 [17].

- Most secondary mathematics teachers have had limited training to use technology in lessons. There are no subject-level standards for technology competency within teacher training, nor is it mandated that technology should be used within the National Curriculum and its associated assessments.

\section{The Cornerstone Maths Project in England}

The Cornerstone Maths project built on the foundations of the SimCalc project in the US, which had demonstrated students' learning gains in the key mathematical topic linear functions in a series of studies [18]. The key features of Cornerstone Maths are:

- Replacement curriculum units that use mathematical representational technologies to enhance the teaching and learning of 'big ideas in mathematics' that are 'hard to teach'.

- Teacher professional development materials, time for professional learning alongside school-based support.

- A phased research project that is 'scaling up' across the country

\subsection{Linear Functions - A Landmark Activity, 'Shakey the Robot'}

To give a sense of the particular transformative mathematical technology developed within the Cornerstone Maths project, a landmark activity from the curriculum unit on linear functions is described.

The curriculum unit is set within a 'realistic' context within which students become developers of games for mobile phones for a fictitious IT design company in which their role is to advise the programmers on the mathematics that will make the game characters move in particular ways - the students use mathematics to analyse and create simulated motion games.

The design of the (web-based) software and the related tasks for students are based on the following principles:

- Multiple mathematical representations show a dynamic simulation with linked representations: animation; Cartesian graph of position-time; table of values; and mathematical function.

PRE-PRINT Clark-Wilson, A. (2017). The Complex Process of Scaling the Integration of Technology Enhanced Learning in Mainstream Classrooms. In G. Costagliola, J. Uhomoibhi, S. Zvacek, \& B. M. McLaren (Eds.), Computers Supported Education: 8th International Conference, CSEDU 2016, Rome Italy, April 21-23, 2016, Revised Selected Papers (pp. 3-13). Cham: Springer International Publishing. 
- Edit functionality enables the simulation to be controlled via the animation, the graph or function.

- Representations can be shown and hidden, as required and/or necessitated.

Figure 3 shows the software for the landmark activity 'Shakey the Robot'.

Figure 3 Shakey the Robot

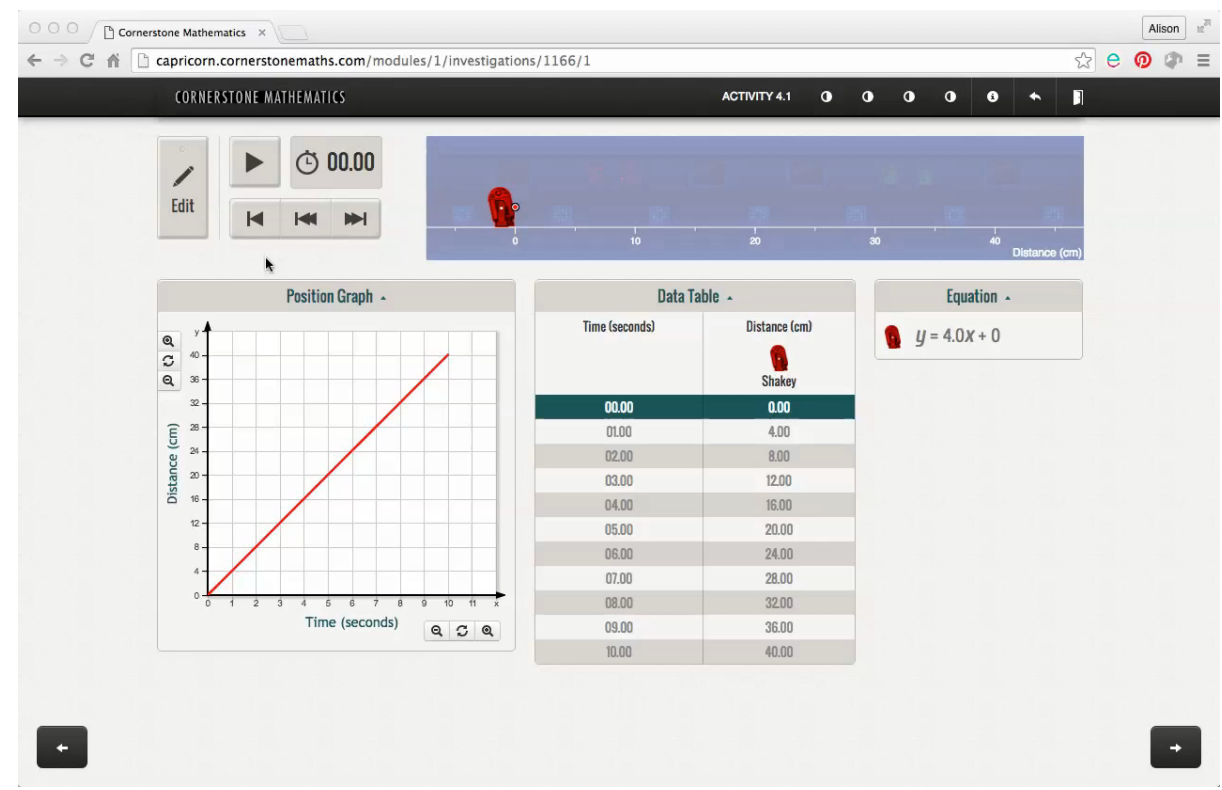

In a traditional introduction to this mathematical content students would be given the mathematical function, $y=f(x)$ and, by substituting values of $x$ into the function, generate a value of $y$ to produce co-ordinate pairs that are then plotted on a Cartesian graph plane. The Cornerstone Maths environment supports a more experiential approach whereby the students observe the effect of a particular function on the position-time relationship for the character and, by editing different features arrive at a more meaningful understanding of, in this case, linear functions. In particular, the resulting mathematical knowledge includes:

- coordinating algebraic, graphical, and tabular representations;

- $y=m x+c$ as a model of constant velocity motion - the meaning of $m$ and $c$ in the motion context.

Within the landmark activity, students are directed to edit Shakey's graph to produce a faster and slower animation and, in doing so, make sense of how speed, position and time are represented in each of the graph, table and function. For teachers, the pedagogical challenges arise as they develop ways to mediate the students' learning in partnership with the technology.

PRE-PRINT Clark-Wilson, A. (2017). The Complex Process of Scaling the Integration of Technology Enhanced Learning in Mainstream Classrooms. In G. Costagliola, J. Uhomoibhi, S. Zvacek, \& B. M. McLaren (Eds.), Computers Supported Education: 8th International Conference, CSEDU 2016, Rome, Italy, April 21-23, 2016, Revised Selected Papers (pp. 3-13). Cham: Springer International Publishing. 
To date, we have worked with over 300 teachers from over 100 diverse schools in England, involving nearly 8000 students aged 11-14 years. Teachers are reporting positive outcomes - both in terms of their students' mathematical learning - and their motivation and attitudes towards learning mathematics. However, how do we decide whether or not we have 'scaled' our innovation?

\section{Conceptualising scaling in education}

\subsection{Scaling educational innovations}

Cordingly and Bell carried out an extensive literature review that resulted in a framework to support how 'scaling' might be conceptualised within the context of educational reform - drawing heavily on the work of Coburn [19], who had conceived four interrelated and overlapping dimensions:

- Depth: Going beyond surface structures and practices to alter beliefs, norms of social interaction and pedagogical principles.

- Sustainability: The innovation can better respond consistently to new demands and changing contexts - requires support mechanisms including a supportive professional community of colleagues within a school.

- Spread: not only increasing numbers (of schools/teachers/students) but also the ways in which reform norms and principles influence identifiable operational structures such as policies, procedures and professional development processes and priorities.

- Ownership: This must shift from an external reform to one controlled internally.

Cordingly and Bell added fifth dimension, purpose or aim, whereby the goal of the innovation must be understood and connected to the starting point [20]. Whilst technology is not specifically excluded, Cordingly and Bell's review did not focus on, nor draw any conclusions in relation to any specific aspects of educational technological innovations.

\subsection{Scaling technological educational innovations}

Hung, Lim and Huang theorised about the scaling of maths and science technology-based educational innovations in Singapore, leading to a product-process model. By products, they refer to the deliverables (performance indicators) of successful scaling, which are commonly defined according to strict numeric outcomes (e.g. the number of teachers, the number of schools, the number of school clusters, etc). The define innovation-scaling as a set of processes "not to be replicated, but instead to be re-created / re-instantiated / re-enacted" [21]. In our Cornerstone Maths research we have applied and expanded Hung et al's construct to give the themed set of products and processes as shown in Table 1 .

$$
10
$$

PRE-PRINT Clark-Wilson, A. (2017). The Complex Process of Scaling the Integration of Technology Enhanced Learning in Mainstream Classrooms. In G. Costagliola, J. Uhomoibhi, S. Zvacek, \& B. M. McLaren (Eds.), Computers Supported Education: 8th International Conference, CSEDU 2016, Rome, Italy, April 21-23, 2016, Revised Selected Papers (pp. 3-13). Cham: Springer International Publishing. 
Table 1 Scaling Cornerstone Maths: Products and Processes

\begin{tabular}{|c|c|c|c|}
\hline Theme & Products & & Processes \\
\hline \multirow[t]{2}{*}{ 1. Geographical reach } & $\begin{array}{l}\text { a) Number of } \\
\text { schools involved }\end{array}$ & $\begin{array}{l}\text { a) } \\
\text { b) }\end{array}$ & $\begin{array}{l}\text { Development of web- } \\
\text { based curriculum activi- } \\
\text { ty system. } \\
\text { Development of teacher } \\
\text { community. }\end{array}$ \\
\hline & $\begin{array}{l}\text { b) Number of local } \\
\text { hubs involved }\end{array}$ & c) & $\begin{array}{l}\text { Development and } \\
\text { maintenance of regional } \\
\text { hub-based offer of pro- } \\
\text { fessional support. } \\
\text { Development of school } \\
\text { clusters, supported by } \\
\text { project team leading to } \\
\text { development of local } \\
\text { hubs with local CM pro- } \\
\text { ject lead. }\end{array}$ \\
\hline \multirow[t]{3}{*}{ 2. School buy-in } & $\begin{array}{l}\text { c) Improved student } \\
\text { attainment }\end{array}$ & e) & $\begin{array}{l}\text { School-devised methods } \\
\text { to evaluate students' } \\
\text { outcomes }\end{array}$ \\
\hline & $\begin{array}{l}\text { d) Number of whole } \\
\text { departments in- } \\
\text { volved }\end{array}$ & f) & $\begin{array}{l}\text { Development of school- } \\
\text { based PD. } \\
\text { Support to embed CM } \\
\text { within local of schemes } \\
\text { of work. }\end{array}$ \\
\hline & $\begin{array}{l}\text { e) Wider use of the } \\
\text { materials }\end{array}$ & h) & $\begin{array}{l}\text { Teacher use of the mate- } \\
\text { rials beyond their origi- } \\
\text { nal project commitment. } \\
\text { (e.g. with older classes }\end{array}$ \\
\hline
\end{tabular}

11

PRE-PRINT Clark-Wilson, A. (2017). The Complex Process of Scaling the Integration of Technology Enhanced Learning in Mainstream Classrooms. In G. Costagliola, J. Uhomoibhi, S. Zvacek, \& B. M. McLaren (Eds.), Computers Supported Education: 8th International Conference, CSEDU 2016, Rome, Italy, April 21-23, 2016, Revised Selected Papers (pp. 3-13). Cham: Springer International Publishing. 


\begin{tabular}{|l|ll|ll|}
\hline & & or revision classes). \\
\hline $\begin{array}{l}\text { 3. } \\
\text { mathematics de- } \\
\text { partment }\end{array}$ & f) & $\begin{array}{l}\text { Number of partic- } \\
\text { ipating teachers in } \\
\text { each school }\end{array}$ & i) & Development of a lead \\
& & practitioner (who may & be the subject leader). \\
& & j) & Development of peer- \\
& & & support for participating \\
& & & \\
& & &
\end{tabular}

Our earlier phases of work, funded by Li Ka Shing Foudndation, focused on extending the geographical reach of Cornerstone Maths, which resulted in the refinement of the web-based curriculum activity system, support for the teacher community and the regional/local professional support through school clusters. However, as the number of schools has increased and our evaluation research has indicated wide variation of outcomes related to Theme 2, the school 'buy-in' of the innovation, our attention has moved to research successful features of 'within-school' scaling that in turn lead to Theme 3, 'penetration within departments'.

\section{$7 \quad$ Implications for further research}

The current phase of Nuffield Foundation-funded research is responding to the following research questions:

- What is the impact on teachers' mathematical knowledge for teaching of their engagement with cycles of professional development and associated teaching of the difficult mathematical concepts; algebraic generalisation, geometric similarity, and linear functions?

- What mathematical knowledge for teaching and mathematical pedagogic practices are desirable for teachers to integrate dynamic visual technologies in their teaching of these concepts?

- What are the design features of professional development activities for lower secondary mathematics teachers that support them to use dynamic, visual technology in ways that become embedded for both the teachers and their pupils and lead to effective learning?

Our methodology involves design-based research cycles of co-development of web-based resources to support 'within school' scaling of Cornerstone Maths working in collaboration with project schools and teachers. We conjecture that, by articulating the specific mathematical knowledge for teaching and associated mathematical pedagogic practices with [Cornerstone] Maths landmark activities, we can produce research-informed professional development resources that better meet teachers' needs.

$$
12
$$

PRE-PRINT Clark-Wilson, A. (2017). The Complex Process of Scaling the Integration of Technology Enhanced Learning in Mainstream Classrooms. In G. Costagliola, J. Uhomoibhi, S. Zvacek, \& B. M. McLaren (Eds.), Computers Supported Education: 8th International Conference, CSEDU 2016, Rome, Italy, April 21-23, 2016, Revised Selected Papers (pp. 3-13). Cham: Springer International Publishing. 
Alongside this, we aim to illuminate the processes of 'within-school' scaling through longitudinal (3 year) case studies in a sample of project schools.

In closing, I would like to highlight for wider consideration three tensions that exist within the educational design community.

1. Do we design technology-enhanced learning for teachers/lecturers that aim to solve epistemological or pedagogical issues that neither recognise? $\boldsymbol{O R}$ do we work with teachers/lecturers to design TEL that takes account of prevailing epistemologies/pedagogies?

2. Do we design 21st century technology-enhanced learning to provide access to 21 st century curricula $\boldsymbol{O R}$ do we design 21 st century technology-enhanced learning to support 19th century curricula?

3. Do we design technology-enhanced learning solution 'because we can' $\boldsymbol{O R}$ do we design and implement technology-enhanced learning to develop $21^{\text {st }}$ century skills/knowledge/practices?

There are no simple answers to these questions, however, whatever you conclude, without a clear understand about how any technology-enhanced learning might scale, the efforts and resources might never realize that early optimism!

\section{Acknowledgements}

The particular research on scaling reported in this paper was funded by the Nuffield Foundation (Award reference 91909) and it involved my close colleagues Celia Hoyles and Richard Noss. In addition, we gratefully acknowledge funding by the Li Ka Shing Foundation for the prior research that took place between 2010-13, which was an intensive collaboration between teams at the London Knowledge Lab, UCL Institute of Education and at the Center for Technology in Learning, SRI International, Menlo Park, USA.

\section{$9 \quad$ References}

1. Skinner, B. F. (1955). Teaching machine and programmed learning. Retrieved from https://www .youtube.com/watch?v=jTH3ob1IRFo

2. Papert, S. (1972). LOGO Programming language. Retrieved from https://www .youtube.com/watch?v=5dZMgdqy7zY

3. Churchhouse, R. F., Cornu, B., Howson, A. G., Kahane, J.-P., van Lint, J. H., Pluvinage, F., Pluvinage, F., Ralston, A. \& Yamaguti, M. (1986). The Influence of Computers and Informatics on Mathematics and its Teaching (Vol. ICMI Study 1). Cambridge: Cambridge University Press.

4. Hoyles, C. \& Lagrange, J. B. (Eds.). (2009). Mathematics Education and Technology - Rethinking the Terrain: The 17th ICMI Study (Vol. New ICMI Study Series , Vol. 13). Berlin: Springer.

PRE-PRINT Clark-Wilson, A. (2017). The Complex Process of Scaling the Integration of Technology Enhanced Learning in Mainstream Classrooms. In G. Costagliola, J. Uhomoibhi, S. Zvacek, \& B. M. McLaren (Eds.), Computers Supported Education: 8th International Conference, CSEDU 2016, Rome, Italy, April 21-23, 2016, Revised Selected Papers (pp. 3-13). Cham: Springer International Publishing. 
5. Clark-Wilson, A., Robutti, O. \& Sinclair, N. (2014). The Mathematics Teacher in the Digital Era: An International Perspective on Technology Focused Professional Development (Vol. 2, Mathematics Education in the Digital Era). Dordrecht: Springer.

6. Clark-Wilson, A., Aldon, G., Cusi, A., Goos, M., Haspekian, M., Robutti, O. \& Thomas, M. O. J. (2014) The challenges of teaching mathematics with digital technologies - The evolving role of the teacher. In P. Liljedahl, C. Nichol, S. Oesterle, \& D. Allan (Eds.), Proceedings of the Joint Meeting of PME 38 and PME-NA 36, Vancouver, Canada, 2014 (Vol. 1,pp. 87-116): University of British Columbia.

7. Guin, D. \& Trouche, L. (1999). The complex process of converting tools into mathematical instruments: The case of calculators. International Journal of Computers for Mathematical Learning, 3(3), pp. 195-227.

8. Artigue, M. (2002). Learning mathematics in a CAS environment: The genesis of a reflection about instrumentation and the dialectics between technical and conceptual work. International Journal of Computers for Mathematical Learning, 7(3), 245-274, doi:10.1023/A:1022103903080.

9. Clark-Wilson, A., Hoyles, C., Noss, R., Vahey, P. \& Roschelle, J. (2015). Scaling a technology-based innovation: Windows on the evolution of mathematics teachers' practices. ZDM Mathematics Education, 47(1), doi:10.1007/s11858-014-0635-6.

10. Hoyles, C. \& Noss, R. (2003). What can digital technologies take from and bring to research in mathematics education? In A. Bishop, M. Clements, C. Keitel, J. Kilpatrick, \& F. Leung (Eds.), Second international handbook of mathematics education. Dordrecht: Kluwer Academic.

11. Winograd, T. \& Flores, F. (1986). Understanding Computers and Cognition: A New Foundation for Design: Ablex Publishing Corp.

12. Clark-Wilson, A., Hoyles, C., \& Noss, R. (2015). Conceptualising the scaling of mathematics teachers' professional development concerning technology. In K. Krainer \& N. Vondrová (Eds.), Proceedings of the Ninth Congress of the European Society for Research in Mathematics Education (pp. 2333-2339). Prague, Czech Republic.

13. Trigueros, M., Lozano, M-D. \& Sandoval, I. (2014). Integrating Technology in the Primary School Mathematics Classroom: The Role of the Teacher. In A. Clark-Wilson, O. Robutti, \& N. Sinclair (Eds.), The Mathematics Teacher in the Digital Era: An International Perspective on Technology Focused Professional Development (pp. 111-138). Dordrecht: Springer.

14. Thomas, M. O. J. \& Palmer, J. (2014). Teaching with digital technology: Obstacles and opportunities. In A. Clark-Wilson, O. Robutti, \& N. Sinclair (Eds.), The Mathematics Teacher in the Digital Era: An International Perspective on Technology Focused Professional Development (pp. 71-89). Dordrecht: Springer.

15. Buteau, C. \& Muller, E. (2014). Teaching Roles in a Technology Intensive Core Undergraduate Mathematics Course. In A. Clark-Wilson, O. Robutti, \& N. Sinclair (Eds.), The Mathematics Teacher in the Digital Era: An International Perspective on Technology Focused Professional Development (pp. 163-188). Dordrecht: Springer.

16. Office for Standards in Education (2012). Mathematics: Made to measure. London: Department for Children, Schools and Families.

17. OECD (2015). Students, Computers and Learning: Making the connection. PISA, OECD Publishing.

18. Hegedus, \& Roschelle, J. (2013). The SimCalc vision and contributions. Netherlands: Springer.

PRE-PRINT Clark-Wilson, A. (2017). The Complex Process of Scaling the Integration of Technology Enhanced Learning in Mainstream Classrooms. In G. Costagliola, J. Uhomoibhi, S. Zvacek, \& B. M. McLaren (Eds.), Computers Supported Education: 8th International Conference, CSEDU 2016, Rome, Italy, April 21-23, 2016, Revised Selected Papers (pp. 3-13). Cham: Springer International Publishing. 
19. Coburn, C. (2003). Rethinking Scale: Moving Beyond Numbers to Deep and Lasting Change. Educational Researcher, 32(6), 3-12.

20. Cordingley, P. and Bell, M. (2007) Transferring learning and taking innovation to scale. London, The Innovation Unit.

21. Hung, D., Lim, K., \& Huang, D. (2010). Extending and scaling technology-based innovations through research: The case of Singapore. In Organisation for Economic Co-operation and Development (Ed.), Inspired by Technology, Driven by Pedagogy: A Systemic Approach to Technology-Based School Innovations (pp. 89-102): OECD Publishing.

PRE-PRINT Clark-Wilson, A. (2017). The Complex Process of Scaling the Integration of Technology Enhanced Learning in Mainstream Classrooms. In G. Costagliola, J. Uhomoibhi, S. Zvacek, \& B. M. McLaren (Eds.), Computers Supported Education: 8th International Conference, CSEDU 2016, Rome, Italy, April 21-23, 2016, Revised Selected Papers (pp. 3-13). Cham: Springer International Publishing. 